\title{
Uma artista completa, a imprensa e a reputação de Guiomar Novaes
}

\author{
[ A full-blown artist, the press and the Guiomar Novaes' reputation
}

\section{Fernando Pereira Binder ${ }^{\mathrm{I}}$}

Partes deste texto estão desenvolvidas no sexto capítulo da tese de doutorado Profissionais, amadores e virtuoses: piano, pianismo e Guiomar Novaes (Escola de Comunicações e Artes - ECA/USP, 20I8).

\begin{abstract}
RESUMO - Na década de I920 Guiomar Novaes (I894-I979) possuía uma posição única no universo artístico brasileiro, posição mantida por toda a sua vida mas que não garantiu a segurança de seu arquivo pessoal. Este artigo relaciona brevemente a fragmentação e as ameaças sofridas pelo acervo da pianista às distinções de gênero entre intérpretes e compositores que existiam (e ainda existem) na chamada música erudita. A cobertura da imprensa de recitais realizados entre I9I3 e I9I4 é usada para investigar a criação da reputação de artista da pianista. $O$ conceito de mundo artístico de Becker (I982) revelou o papel de jornais e revistas para mobilizar expectativas e afetos no público paulista e brasileiro, colaborando, assim, para torná-la um símbolo nacional. • PALAVRAS-CHAVE . Crítica musical; mundo artístico; reputação artística; pianolatria; arquivo pessoal de
\end{abstract}

intérprete. • ABSTRACT - In the I920s Guiomar Novaes (1894-I979) had a unique position in the Brazilian artistic world, a position maintained throughout his life but that did not guarantee the security of her personal archive. This paper briefly relates the fragmentation and threats suffered by the pianist's collection to the gender distinctions that exist between interpreters and composers that existed (and stil exists) in the so-called classical music. The press coverage of recitals conducted between I9I3 and I9I4 is used to investigate the creation of the pianist's reputation as an artist. Becker's concept (I982) of the art world revealed the role of newspapers and magazines in mobilizing expectations and affections in the public of São Paulo and Brazil, and thereby collaborating to make her a national symbol. - KEYWORDS . Musical criticism; art world; artistic reputation; pianolatria; performer personal archive.

Recebido em 25 de julho de 2018

Aprovado em 2 de novembro de 2018

BINDER, Fernando Pereira. Uma artista completa, a imprensa e a reputação de Guiomar Novaes. Revista do Instituto de Estudos Brasileiros, Brasil, n. 7I, p. I58-I80, dez. 2018.

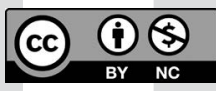

DOI: http://dx.doi.org/Io.II6o6/issn.23I6-90IX.voi7IpI58-I80

I Escola Municipal de Música, Fundação Theatro Municipal de São Paulo (EMM, São Paulo, SP). 


\section{OS DESCAMINHOS DA MEMÓRIA DA MAIOR BRASILEIRA VIVA}

Em abril de I925 a revista Fon-Fon! apresentou o resultado de seu concurso nacional para eleger "os maiores brasileiros vivos". As personalidades mais votadas pelos leitores do periódico carioca foram apresentadas em um quadro de retratos estampado em página dupla (Figura I).

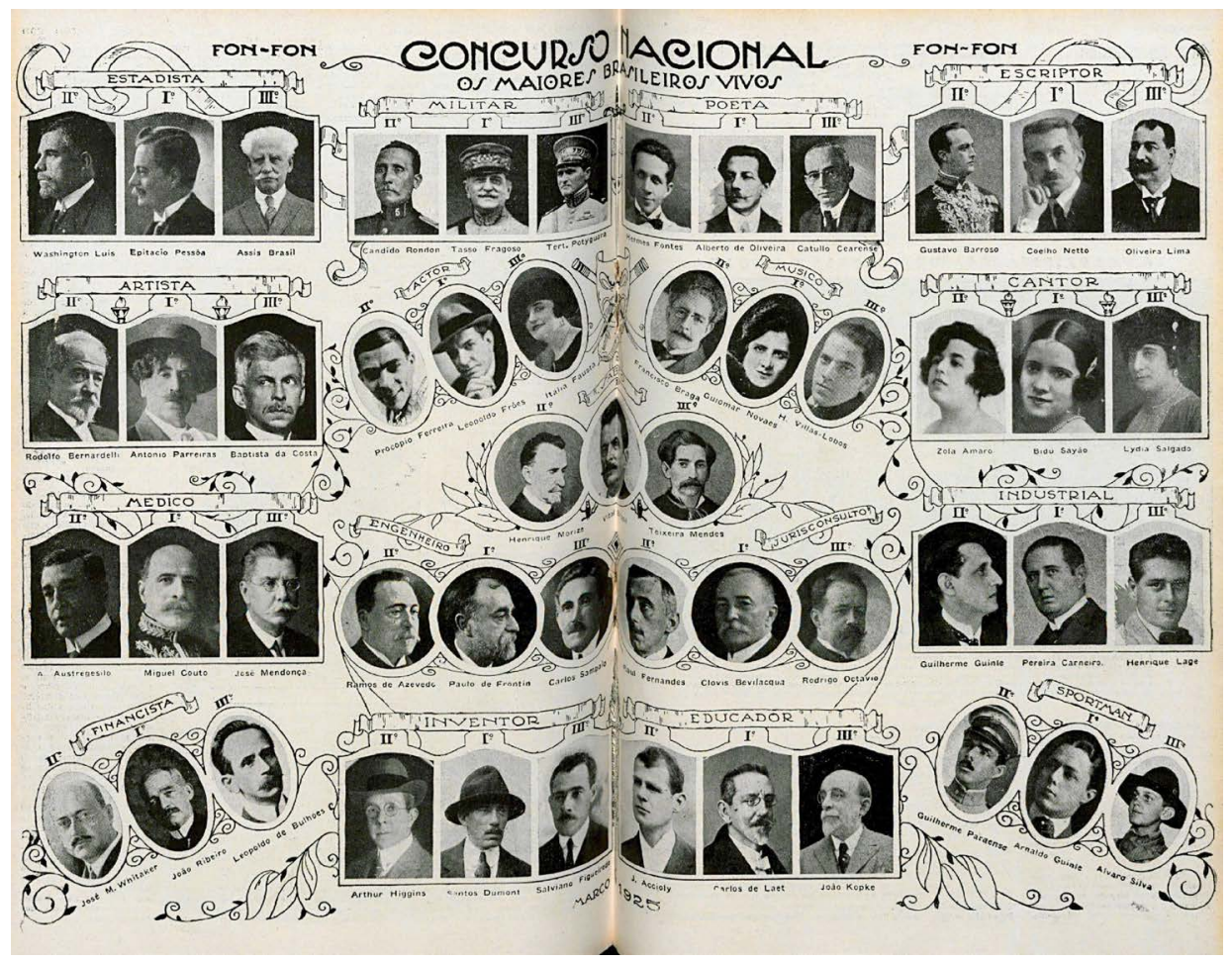

Figura 1 - Resultado do concurso nacional “Os maiores brasileiros vivos” (Fon-Fon!, n. 14, 4 de abril de 1925, p. 46-47) 
Os 5 I eleitos para esse "panteão" da Primeira República foram divididos em I7 categorias. As mulheres eram apenas cinco e estavam em três categorias: cantor, ator e músico. Apesar do gênero masculino no rótulo - não havia homens entre os cantores -, as vencedoras foram Bidu Sayão, Zola Amaro e Lydia Salgado. Entre os atores, Itália Fausta ocupou a terceira posição, atrás de Leopoldo Fróes e Procópio Ferreira. Comparada às suas colegas, a vitória de Guiomar Novaes foi dupla: conquistou o primeiro lugar em sua classe superando competidores homens. Guiomar foi eleita a maior musicista viva do Brasil à frente dos compositores Francisco Braga e Heitor Villa-Lobos.

Apesar dessa altíssima reputação, que foi mantida por toda a sua vida, a memória de Guiomar não teve a mesma sorte que a de seu colega de geração e de pódio. Enquanto a de Villa-Lobos é preservada em um museu que leva seu nome, o arquivo pessoal de Guiomar Novaes começou a dispersar-se com ela ainda em vida.

Em correspondência trocada entre os musicólogos Arnaldo Senise e Cleofe Person de Mattos, em dezembro de I983, surgem as primeiras notícias sobre o extravio do espólio de Guiomar (falecida em I979) que estava "parcialmente disponível, por ter-se perdido grande parcela”. A parte que restava e que fora inspecionada por Senise passara às mãos de Ney Ávila Blanco. Aficionada por Guiomar e colecionadora de antiguidades, Ney descobriu o acervo ao responder a um anúncio de venda de móveis. Esse primeiro expurgo ocorreu durante a mudança da pianista da famosa casa na rua Ceará, 457, no bairro de Higienópolis, para um apartamento em Cerqueira César. Relembrando a ocasião, Ávila conta que

Guiomar mudou-se várias vezes no fim da vida. E, com essas mudanças, o material histórico ficou todo guardado em uma garagem. Com medo da possibilidade de aquele acervo ser danificado, recolhi e guardei muitas destas coisas. Tenho discos, roupas, sapatos, fotos, alguns rolos de pianola, correspondência e material de imprensa. E quero que tudo isso seja restaurado e preservado para o Brasil. (MEDEIROS; SAMPAIO, 2OII, p. I84).

Até recentemente essa coleção estava em Piracaia, cidade do interior do estado de São Paulo, para onde Ney se mudara e onde faleceu em 20I4. Em agosto de 20I8, partes desse acervo foram recolhidas ao Instituto Piano Brasileiro, em Brasília. Uma parcela foi resgatada dentro do imóvel onde Ney morou, outra parte foi recolhida na rua em uma caçamba de entulho:

Para a limpeza do casarão vendido, os familiares de Ney Ávila colocaram uma caçamba de entulhos em frente o imóvel. Entre restos de papéis, plantas e lixo, outra parte do acervo pertencente à falecida proprietária foi encontrada contendo diversos livros, partituras e mais itens sobre a pianista Guiomar Novaes. (SPECHT, 20I8).

2 Acervo Cleofe Person de Mattos, série Atividades Institucionais/Associativas, subssérie Sociedade Brasileira de Musicologia. Disponivel em: 〈http://www.acpm.com.br/CPM_5I-II-03.htm> (item I2). 
Outro lote de documentos e objetos de Guiomar Novaes está nas mãos de João Antônio Parizoto, que o herdou do professor de piano Ciro Gonçalves Dias Júnior, falecido em 20I7, de quem João foi assistente por muitos anos. Ciro conheceu Guiomar em I952, e conviveu com ela e a família por 25 anos (MEDEIROS; SAMPAIO, 20II, p. I86).

Como explicar o triste destino dos documentos de uma das artistas brasileiras mais importantes do século XX? Em primeiro lugar é preciso ter em vista a opção da pianista em manter sua vida pessoal reservada e distante do público, desestimulando o culto à sua personalidade 3 .

Outro motivo para a dispersão do arquivo pessoal de Guiomar foi a falta de uma instituição que o recebesse e o preservasse. Foi isso o que fez Arminda Villa-Lobos, a segunda esposa do compositor carioca, ao criar o Museu Villa-Lobos, que ela dirigiu por mais de duas décadas 4 : institucionalizar o acervo do marido. Enquanto esteve viva, Ávila assumiu a função da família em guardar e preservar os documentos pessoais da pianista. Com a morte da colecionadora o acervo ficou desprotegido e quase acabou tragicamente perdido.

Mas qualquer comparação entre os destinos dos dois arquivos precisa considerar a natureza e o status distintos das atividades artísticas de seus formadores: Guiomar era pianista, Villa-Lobos, compositor. Em seus recitais, concertos e registros fonográficos ela executava música que não era sua, produzia recriações de obras de arte criadas por outros artistas, por compositores como Villa-Lobos. Existe uma farta literatura sobre a clivagem de gênero na chamada música erudita mostrando como a atividade de compositor foi socialmente construída como masculina ${ }^{5}$. No mundo do piano do qual Guiomar participou, a carreira de intérprete estava aberta às mulheres, mas as outras áreas, como a composição, a crítica e o ensino virtuosístico, continuavam dominadas pelos homens (cf. TOFFANO, 2007, p. I60).

Ocorre que as instituições dedicadas à memória musical ainda são fortemente pautadas para a preservação de obras originais e não suas interpretações 6 . Por isso, os acervos que acabam selecionados para a preservação são aqueles que possuem partituras, ou seja, aqueles que preservam um tipo específico de documento escrito, documentos que registram as obras musicais originais de um compositor. Portanto a prática atual de preservação de acervos musicais reproduz as distinções de gênero registradas na produção e recriação de obras artísticas musicais.

Existem dois trabalhos biográficos importantes sobre Guiomar Novaes: a tese de

3 Sobre o assunto, ver: Binder, 2017.

4 O Museu Villa-Lobos foi criado em I96o por Clóvis Salgado, ministro da Educação e Cultura durante o governo do presidente Juscelino Kubitschek. Para a história de sua criação e o papel de Arminda nele, ver: Belchior; Antunes, 20II.

5 Para as construções sobre gênero, criatividade artística e profissionalismo, ver: Citron, I993. Para a afirmação e negação da feminilidade nas atividades de intérprete e compositor, ver: Green, I997. Sobre o dilema entre compositora e intérprete, ver: Silva, 2008.

6 Em outra oportunidade examinei a relação entre intérpretes, arquivos e memória (BINDER, 20I7). 
livre-docência de Maria Stella Orsini (I988, v. I, p. II)7, um monumento em quatro volumes fartamente documentado, e o livro dos jornalistas Luciana Medeiros e João Carlos Sampaio (MEDEIROS; SAMPAIO, 20II, p. 2I), cujo foco é a carreira de Guiomar nos Estados Unidos.

A trajetória profissional de Guiomar Novaes foi analisada por Jaci Toffano (2007) e Dalila Carvalho (20I2). Toffano (2007, p. I7-22) estudou a profissão de pianista de concerto no Brasil em dois períodos distintos: na década de I920 e no fim do século XX. Carvalho (20I2, p. 22) estudou o imbricamento das convenções de gênero na construção da vocação profissional e o exercício do ofício musical. Em suas conclusões, ambas afirmam que o êxito de Guiomar representava uma transgressão às normas sociais de seu tempo, segundo as quais a mulher deveria dedicar-se à família e aos filhos (TOFFANO, 2007, p. I37; CARVALHO, 20I2, p. 67).

A distribuição desproporcional de gênero entre os premiados do concurso "Os maiores brasileiros vivos" deixa claras as desigualdades de acesso e sucesso nos mundos do trabalho e do conhecimento. Já a concentração das mulheres nas carreiras artísticas mostra a importância delas como lugar de afirmação da excelência feminina. Se a carreira de pianista internacional representava uma transgressão ao ordenamento social, como Guiomar Novaes conquistou o status de Artista?

Um problema que enfrentei em meu doutoramento ao estudar Guiomar Novaes foi não poder contar com fontes organizadas e acessíveis8. No caso de Guiomar, desvendar o papel de jornais e revistas torna-se especialmente importante pois a imprensa periódica tem sido o principal manancial de informação sobre a carreira da pianista.

Para entender como Guiomar ascendeu ao topo da hierarquia musical brasileira, utilizo como referencial teórico os conceitos de reputação e mundo artístico propostos pelo sociólogo americano Howard Becker (I982). Tais ferramentas revelam a rede de pessoas e convenções que atuaram na construção social da reputação da artista de Guiomar Novaes.

\section{UMA DATA ESQUECIDA}

Guiomar Novaes nasceu em São João da Boa Vista em I894. Por volta de I902 ela passou a estudar piano com o italiano Luigi Chiaffarelli (I856-I923), àquela época um dos mais respeitados professores do país. Em fins de I909 ela partiu para a Europa como bolsista do governo paulista para estudar com Isidor Phillipp no Conservatório de Paris, onde conquistou o prêmio de láurea da escola, o Premier Prix, em I9II.

Guiomar permaneceu na Europa até meados de I9I3. De volta a São Paulo em agosto, dali a um mês ela debutava no Theatro Municipal. O palco, que mal completara dois anos, recebeu-a em I5 de setembro de I9I3.

7 A tese de livre-docência de Orsini (I988) posteriormente foi resumida e publicada em forma de livro (ORSINI, I992).

8 Durante meu doutoramento, realizado entre 20I4 e 20I8, que versou sobre a pianista, procurei Ciro Dias e Marcia Ávila de Albuquerque (a herdeira de Ney Ávila). Ambos me negaram o acesso aos documentos que possuíam (BINDER, 20I8). 
Hoje, sua estreia no Municipal está praticamente esquecida. À medida que sua carreira avançou, esse concerto perdeu importância frente aos realizados em Nova York, no final de I9I5, e à sua participação polêmica na Semana de Arte Moderna em I922. Esse processo de reavaliação, reordenamento e esquecimento de êxitos e conquistas em uma longuíssima carreira, como foi a de Guiomar Novaes, não é surpreendente. Ainda assim é preciso reconhecer o papel que a ausência de documentos sobre a ocasião causa.

A inexistência de um programa ${ }^{9}$ do concerto $^{\text {Io }}$ de estreia de Guiomar no Theatro Municipal certamente contribuiu para seu esquecimento. Orsini (I99I, p. 88), por exemplo, comenta laconicamente: "Em I5 de setembro de I9I3, fez sua rentrée no Municipal de São Paulo". A importância desse concerto pode ser medida pela importância do palco, um símbolo do projeto artístico e civilizatório da burguesia cafeeira paulista, "um teatro monumental [que] representava um dos pilares de sua administração modernizadora" ${ }^{\text {II. }}$. Hoje, engolido pelos prédios ao seu redor, o Municipal perdeu muito da monumentalidade original ${ }^{12}$.

Outros concertos, cujos programas foram preservados, ganham uma dimensão que esse jamais terá, pois deixaram um artefato que pode ser reproduzido em livros, revistas e na internet. O programa é um testemunho histórico do evento, que, privado de seu vestígio material, tem sua rememoração e perpetuação embaraçada, mesmo que sua informação possa ser recuperada em outras fontes. Programas de concerto são documentos/monumentos (cf. LE GOFF, 2003, p. 528-530) que desempenham papel fundamental para a construção da reputação dos músicos.

\section{O disCURSO DAS CAPAS: AFETOS E EXPECTATIVAS NA IMPRENSA PAULISTANA}

A reputação de um artista é a soma dos valores atribuídos às suas obras (BECKER, I982, p. 23). Logo, o valor que hoje conferimos a Guiomar Novaes é diferente daquele dado pelos paulistas em meados da década de I9Io. Para nós a carreira de concertista internacional foi construída a partir dos Estados Unidos. A projeção obtida na América do Norte marcou-a tão fortemente que, do início de sua carreira na Europa, sobrevivem em sua biografia como episódios significativos o exame de admissão no Conservatório em I909 e a conquista do Premier Prix em I9II. No concerto de estreia no Theatro Municipal de São Paulo em I9I3, a carreira de Guiomar estava começando.

Os paulistas acompanharam sua trajetória na Europa pela imprensa local. Jornais

9 Programa de concerto é um impresso com informações sobre o espetáculo. No início do século XX era uma pequena folha avulsa com a lista das obras e seus autores.

Io Modernamente, chamaríamos a estreia de Guiomar de recital, pois ela apresentou-se sozinha. Mantive a palavra "concerto", pois este era o termo corrente na época.

II A administração do prefeito Antônio Prado (THEATRO MUNICIPAL, 20II, p. 27).

I2 "[...] o seu espetacular potencial cenográfico, dominando todo o Vale do Anhangabaú, a partir do topo da colina do Chá. [...] Seu efeito simbólico arquitetônico e urbanístico externo se equiparava ao prodigioso poder de catalisação cultural que emanava internamente do seu palco. Nesse sentido, o teatro atuava como uma caixa de emissão e repercussão de símbolos sem igual” (SEVCENKO, I992, p. 232). 
e revistas do Rio de Janeiro e São Paulo noticiavam suas apresentações, as críticas feitas na imprensa europeia e até cartas de brasileiros que a viram e ouviram por lá.

Certamente um pequeno grupo de pessoas conseguiu escutar Guiomar antes da estreia em algum sarau em um palacete burguês ou na casa de seu ex-professor. Outra oportunidade que o público de especialistas - críticos, professores e aficionados bem relacionados - tinha para julgar os méritos e fraquezas dos pianistas eram as apresentações nos salões das lojas de música e dos grandes jornais. Alheio a esses círculos, o restante do público dependia da imprensa, que informava sobre a presença e a fama dos músicos de passagem pela cidade. Portanto, olhar a cobertura prévia dos concertos nos jornais revela um discurso endereçado a um público leigo mais numeroso, que talvez nem pudesse ir ao teatro. A cobertura da imprensa nos mostra uma forma de comunicação em que fotos, manchetes, legendas e notícias foram usadas para criar e mobilizar expectativas e afetos em seus leitores.

Em 20 de junho de I9I3, Guiomar Novaes estampava a primeira página do Correio Paulistano (Figura 2 - lado esquerdo). Uma fotografia sua de corpo inteiro noticiava retumbantemente que a pianista retornaria a São Paulo. Essa mesma fotografia foi reproduzida dali a dois meses, quando Guiomar chegou à cidade; em sua legenda lia-se: "a notável pianista chega hoje a S. Paulo" (Correio Paulistano, n. I7.889, 20 de agosto de I9I3, p. 2). Dessa vez a notícia estava na segunda e não na primeira página. Finalmente, em 2I de agosto, o Correio descrevia a recepção dada a ela no dia anterior na gare da Luz, onde seu ex-professor e suas ex-colegas a esperavam.
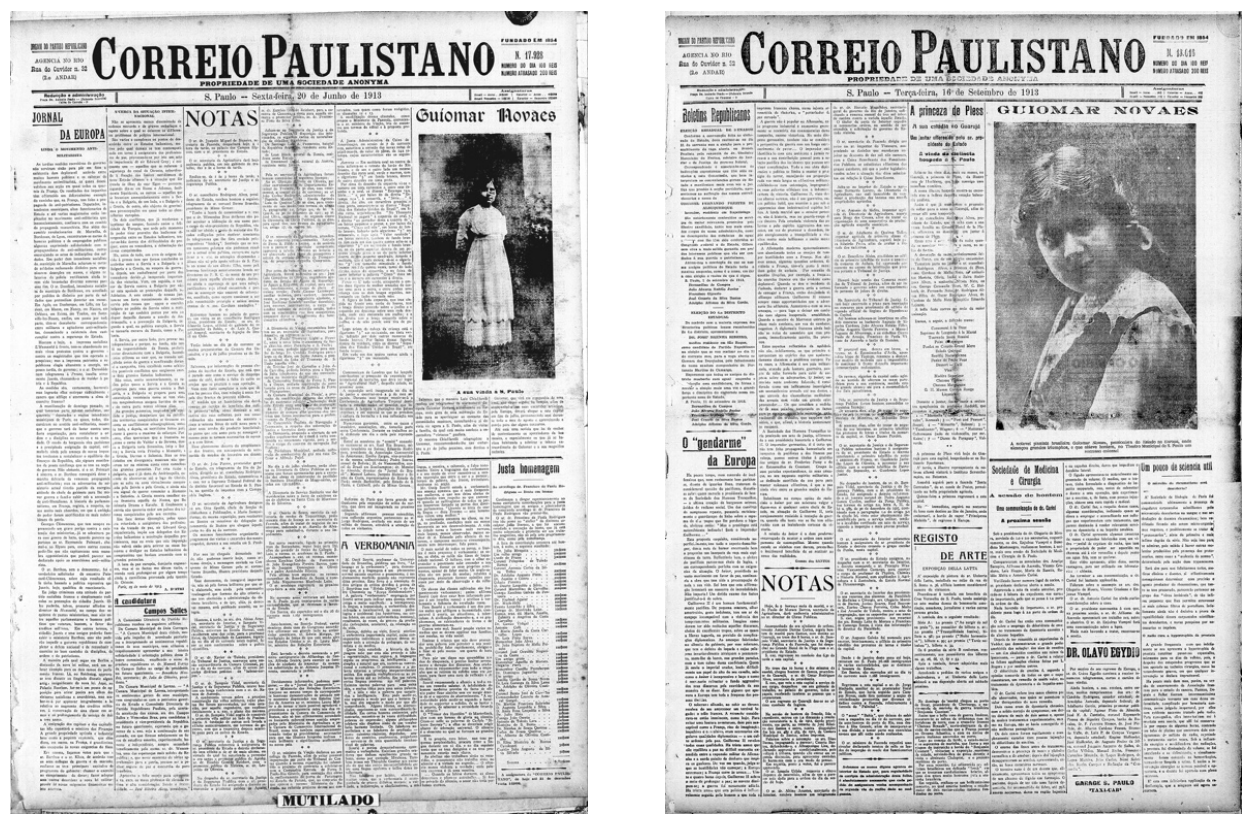

Figura 2 - No lado esquerdo, o anúncio do retorno de Guiomar Novaes a São Paulo; no direito, a foto comemorando o concerto no Theatro Municipal (Correio Paulistano, n. I7.928, 20 de junho de I9I3, p. I; n. I8.0I6, I6 de setembro de I9I3, p. I) 
A forma como o Correio Paulistano cobriu o retorno de Guiomar era a mesma dispensada às autoridades de Estado e do clero, às personalidades da política e às celebridades das letras e das artes: primeiro se noticiava o agendamento da viagem, no dia da chegada prevenia-se o público sobre o fato, por último descrevia-se a recepção feita na Estação da Luz. Ou seja, a convenção jornalística informava a um leitor pouco inteirado no mundo do piano paulistano que uma grande artista chegava à cidade.

Em 6 de setembro, o nome sem a imagem de Guiomar voltava à primeira página do Correio. O título da matéria sobre sua estreia resume bem o tom da cobertura dada pelo jornal: "A grande pianista brasileira dará um concerto em S. Paulo - No Theatro Municipal - Vai ser um extraordinário sucesso" (Correio Paulistano, n. I8.006, 6 de setembro de I9I3, p. I).

Ainda naquele mês Guiomar voltou a ser assunto de capa no Correio Paulistano outras três vezes: a última delas foi no dia seguinte ao concerto. Nessa ocasião seu retrato ocupou cerca de $20 \%$ da primeira página (Figura 2 - lado esquerdo); em sua legenda lia-se: "A notável pianista brasileira Guiomar Novaes, pensionista do Estado na Europa, onde alcançou grandes triunfos, e que obteve ontem, no Theatro Municipal de S. Paulo, um sucesso colossal" (Correio Paulistano, I6 de setembro de I9I3, p. I).

A cobertura dada por $O$ Estado de S. Paulo começou em um tom diferente do de seu concorrente. Não houve menção sobre os preparativos da viagem de volta, e a recepção na Estação da Luz recebeu poucas, mas bastante elogiosas, linhas: "uma virtuose de qualidades notáveis e uma pianista que faz honra ao nome paulista" $(O$ Estado de S. Paulo, n. I2.664, 2I de julho de I9I3, p. 2 - grifos meus). Diferentemente do Correio, a primeira notícia sobre o concerto no Theatro Municipal foi escondida pelo Estado (Figura 3 - lado esquerdo). Colocada em uma posição de pouca visibilidade e separada por uma virada de página, a notícia mostra um claro desprestígio. $\mathrm{Da}$ mesma forma, o estilo e os elogios no texto do Estado eram mais sóbrios e comedidos:

Estamos certos de que esse concerto marcará época no nosso microcosmos artístico. É que a jovem virtuose volta-nos consagrada pelos centros mais cultos da velha Europa, onde o seu brilhante talento recebeu as homenagens dos mais autorizados críticos da arte. [...] todas as preciosas qualidades que a tornam hoje, no mundo artístico, mais alguma coisa do que uma menina prodígio, e sim, uma artista na mais elevada acepção da palavra. (O Estado de S. Paulo, n. I2.680, 6 de setembro de I9I3, p. 5-6 - grifos meus). 

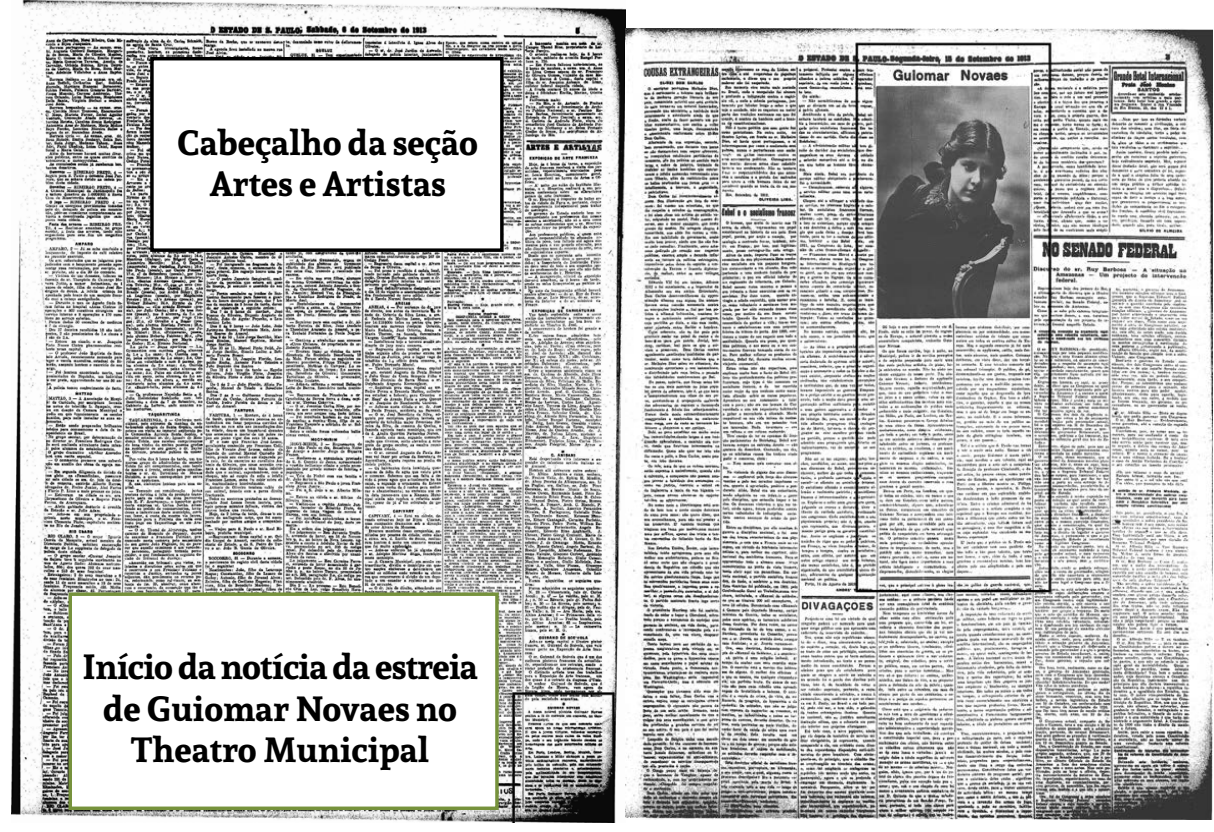

Figura 3 - Lado esquerdo, primeira parte da matéria sobre a estreia de Guiomar Novaes no Theatro Municipal; lado direito, matéria no dia do concerto (O Estado de S. Paulo, 6 de setembro de I9I3, p. 5-6; n. I2.689, I5 de setembro de I9I3, p. 3)

Os preparativos para o concerto apareceram regularmente em pequenas notas nos dois jornais: falavam do piano cedido ao teatro (o mesmo usado pelo virtuose português Viana da Motta em sua última passagem pela cidade), o local de venda dos bilhetes e a procura por eles, a disputa pelos melhores lugares, os convites feitos às autoridades, as flores encomendadas, a preparação dos estrondosos aplausos, os familiares da pianista e os viajantes ilustres que partiam de suas cidades e vinham a São Paulo em razão do concerto etc. No dia I3 de setembro, o Estado informava que a lotação estava quase tomada, o Correio celebrava "essa festa de arte, que, como é de prever, consagrará definitivamente a nossa distinta patrícia” (Correio Paulistano, n. I8.0I3, I3 de setembro de I9I3, p. 3).

De alguma forma as altas expectativas afetaram a redação do Estado e, na edição do dia do concerto, a exaltação venceu a sobriedade. No corpo do texto lia-se: "Os que forem ouvi-la, logo à noite, ao Municipal podem ir de ouvidos prontos e de espírito preparado para ouvir uma das mais perfeitas artistas do piano, hoje existentes no mundo. Não há nisso nenhum exagero da nossa parte” (O Estado de S. Paulo, I5 de setembro de I9I3, p. 3- grifos meus).

Nas páginas do Estado Guiomar começou como "virtuose de qualidades notáveis", passou a "artista na mais elevada acepção" e, finalmente, foi celebrada como uma das mais "perfeitas artistas” do mundo. A perfeição foi alcançada no dia de sua estreia e com ela a fotografia da pianista finalmente era estampada pelo jornal (Figura 3-lado direito). Nas páginas do Estado a presença de ilustrações fotográficas era rara ${ }^{\mathrm{I3}}$. Ou

I3 Segundo levantamento de Telma Madio (2007, p. 6), em todo o ano de I9I3, o Estado colocou apenas II fotografias em suas páginas. O estudo considerou apenas imagens de fontes reconhecidamente fotográficas. 
seja, a mudança de opinião do jornal foi marcada por um recurso gráfico excepcional. A modernidade técnica coroava a alta reputação atribuída a Guiomar.

A presença de imagens na capa do Correio Paulistano tornou-se diária em 7 de julho de I9I2. A partir daquele domingo, o canto superior direito da primeira página passou a ser o espaço costumeiro para exibir estadistas, monumentos, grandes fatos, feitos e heróis do momento. Entre junho e setembro, Guiomar Novaes figurou várias vezes na galeria das celebridades que desfilavam na primeira página do jornal.

A entusiasmada cobertura realizada pelo Correio Paulistano explica-se em parte pela ligação do jornal ao Partido Republicano Paulista (PRP). O partido controlou a política e o governo paulista durante boa parte da Primeira República, e o Correio era o órgão de comunicação oficial do partido, posição explicitamente colocada em seu cabeçalho ${ }^{\mathrm{It}}$. Não eram gratuitas, portanto, as sucessivas referências à participação do governo paulista em prol da educação de Guiomar publicadas no Correio.

Uma pesquisa mais extensa nos periódicos da época pode nos revelar detalhes sobre a importância, o significado e os efeitos dessa exposição para a reputação dos artistas. Do que se sabe até o momento, Guiomar Novaes foi a primeira pianista paulista a ter sua fotografia nas manchetes dos jornais, a ter seu rosto exposto nas tabacarias dos cafés e estações ferroviárias - os postos de vendas usuais desses periódicos na cidade -, a ter seu nome apregoado pelos bambinos, os garotos que vendiam jornais e revistas nas ruas do centro de São Paulo ${ }^{\text {I5. }}$.

\section{Artista COMpleta OU Não?}

A crítica de Félix de Otero sobre a estreia de Guiomar Novaes publicada em $O$ Estado de S. Paulo (n. I2.690, I6 de setembro de I9I3, p. 4) desafinou o coro dos paulistas. Gaúcho com formação musical feita em Berlim, Otero se estabeleceu em São Paulo em I894, atuando como professor de piano, compositor e crítico. Ele foi uma figura importante no periodismo musical da época, foi colaborador e redator-chefe da revista Música para Todos (I896-I899), criou e dirigiu a Revista Artística (I899-I90I) e durante muitos anos foi o crítico musical do Estado. Suas posições germanófilas e wagnerianas em um meio afrancesado e dominado pela ópera italiana renderam-lhe polêmicas e desavenças, inclusive com Luigi Chiaffarelli, o professor de Guiomar.

Embora Otero reconhecesse o talento de Guiomar e os avanços que ela fizera na Europa, o programa e o desempenho de Guiomar não foram convincentes. As obras escolhidas não eram de grande responsabilidade, e a interpretação dada a elas não teria sido tecnicamente perfeita. A interpretação dada à Sonata n. I7, op. 3I, n. 2 "Tempestade", de Beethoven, era estilisticamente inadequada. Na Marcha turca das ruínas de Atenas, de Beethoven, os efeitos dinâmicos foram insuficientes, faltava vigor físico à pianista. Mas o que provocou a ira dos paulistas contra Otero foi a afirmação de que Guiomar não era uma artista acabada. Para ele, a propalada perfeição artística da pianista era produto de um amor-próprio patriótico inconsciente que precisava ser

I4 O PRP era a voz da oligarquia cafeeira paulista, era a fala do estado paulista (cf. THALASSA, 2007, p. 80-8I). I5 Sobre os bambini e os pontos de venda dos periódicos, ver: Martins, 200I, p. 232-234. 
alimentado a qualquer custo. A incompletude de Guiomar devia-se a sua juventude e a sua formação incompleta:

Do completo artista-virtuose dos nossos dias exige-se uma cultura geral muito superior que o leve a assenhorar-se com perícia de todos os segredos da sua arte e lhe permita pisar com a máxima firmeza e convicção no terreno acidentado da Arte geral.

Inúmeros exemplos testemunham que só com a experiência de uma idade madura e com a segura observação adquirida em contínuos e prolongados estudos se consegue a formação de uma pronunciada individualidade artística.

[...]

Percorra a senhorita Guiomar as páginas da história de nossa arte e verá que os Imortais que vivem no Parnaso não tiveram a ele fácil acesso. O "gradus ad Parnassum" é escabroso e exaustivo e os que o percorrem não se apoiam nos sucessos fáceis e fugazes - porque são frágeis. (O Estado de S. Paulo, I6 de setembro de I9I3, p. 4).

Mais do que a intepretação, Otero criticava, de forma paternalista e enviesada, a formação incompleta de Guiomar - ela não possuiria conhecimentos sobre estética e linguagem musical (como contraponto, harmonia, forma e instrumentação, por exemplo). Não existem notícias de que Guiomar tenha estudado qualquer uma dessas disciplinas, nem quando foi aluna de Chiaffarelli, nem quando esteve em Paris ${ }^{16}$. Aliás, Chiaffarelli teve atitudes distintas em relação à formação musical de João de Souza Lima ${ }^{17}$, outro menino prodígio que também foi seu aluno. Souza Lima foi encaminhado para estudar composição com Agostino Cantù, professor do Conservatório Dramático e Musical de São Paulo.

A crítica de Otero foi uma “declaração de guerra” a Vicente de Carvalho. Membro das academias Paulista e Brasileira de Letras, Vicente era um intelectual de enorme prestígio. Em 20 de setembro ele publicou o primeiro de uma série de oito artigos nos quais refutava as afirmações de Otero, criando uma acalorada polêmica que ecoou fortemente na imprensa paulistana. A principal fonte de seus argumentos foram as críticas aos concertos de Guiomar na Europa, cujos elogios, por serem de estrangeiros, estariam isentos do "patriotismo inconsciente" (O Estado de S. Paulo, n. I2.695, 2I de setembro de I9I3, p. 7) denunciado por Otero.

Outro motivo para aquela escolha era o reconhecimento que Vicente fazia de si: sendo leigo em matéria musical ele era incapaz de julgar os méritos propriamente musicais de Guiomar. Portanto, não surpreende que, em seu oitavo e derradeiro artigo, ele procure justificar o reconhecimento público ao qual Guiomar faria jus com argumentos de forte apelo emocional. Nesses argumentos, Carvalho mobiliza três componentes fundamentais para entender a dimensão do fenômeno Guiomar Novaes: a pátria, a civilização e o amor.

I6 Guiomar tomou aulas de análise musical com Furio Franceschini, mas isso foi em data posterior ao período analisado (cf. OLIVEIRA, I98I, p. 59).

I7 Souza Lima nasceu em São Paulo e iniciou seus estudos de piano com o irmão José Augusto. Depois dos estudos com Chiaffarelli, seguiu para o Conservatório de Paris com bolsa do Pensionato Artístico. Além de pianista teve uma carreira importante como maestro. Publicou uma autobiografia (LIMA, I98I). 
A essa artista, que não veio procurar em nós aplausos sem eco de que não precisa e sim nosso carinho, de tanta valia para o seu coração afetuoso; a essa patrícia, que não nos deve quase nada, e a quem nós devemos a sua glória, em que participamos; a essa artista maravilhosa que é nossa patrícia, que tanto nos honra e tanto nos ama, não neguemos o que lhe podemos dar: o nosso entusiasmo enternecido.

[...]

Para que, pela nossa ingratidão contrastando com as seduções do mundo que a aclama, não a desliguemos de nós; para que em toda parte onde a aclamarem, e no seu coração, ela seja sempre como é hoje, a brasileira, "la brèsilienne", "la brasiliana", "the Brazilian", "die Brazilierin” Guiomar Novaes. (O Estado de S. Paulo, n. I2.7I7, I3 de outubro de I9I3, p. 6).

Para Vicente de Carvalho, Guiomar chegara consagrada da Europa, não era o reconhecimento de seu valor que ela buscava no Brasil, as "palmas sem ecos", antes o carinho e o afeto. Guiomar dava aos brasileiros motivos para se orgulharem de si mesmos e de sua nacionalidade. $O$ motivo de orgulho não se assentava na diferença com os europeus, mas em sua semelhança: a música, o instrumento, os compositores e os valores estéticos eram os estabelecidos pelo Velho Mundo. Guiomar os venceu no campo e pelas regras deles. Aquela pequena paulista, que alguns daqueles paulistas conheceram ainda menina, realizou o sonho dourado da elite republicana: éramos ao mesmo tempo brasileiros e europeus.

Não foram só os textos de jornais e revistas os únicos canais pelos quais a polêmica liderada por Vicente de Carvalho se desenrolou. Desenhos, caricaturas e piadas logo foram usados contra Otero. Na contenda, sua militância em favor de Richard Wagner (Figura 4) e as antigas divergências com Chiaffarelli (Figura 5) foram mobilizadas na revista $O$ Pirralho por Juó Bananère e Voltolino para criticá-lo. 


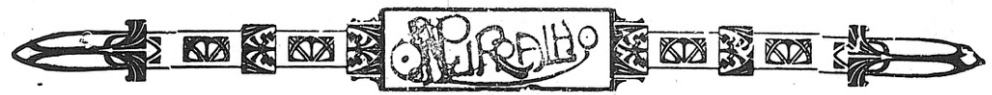

Wagner em palestra com Guiomar Novaes

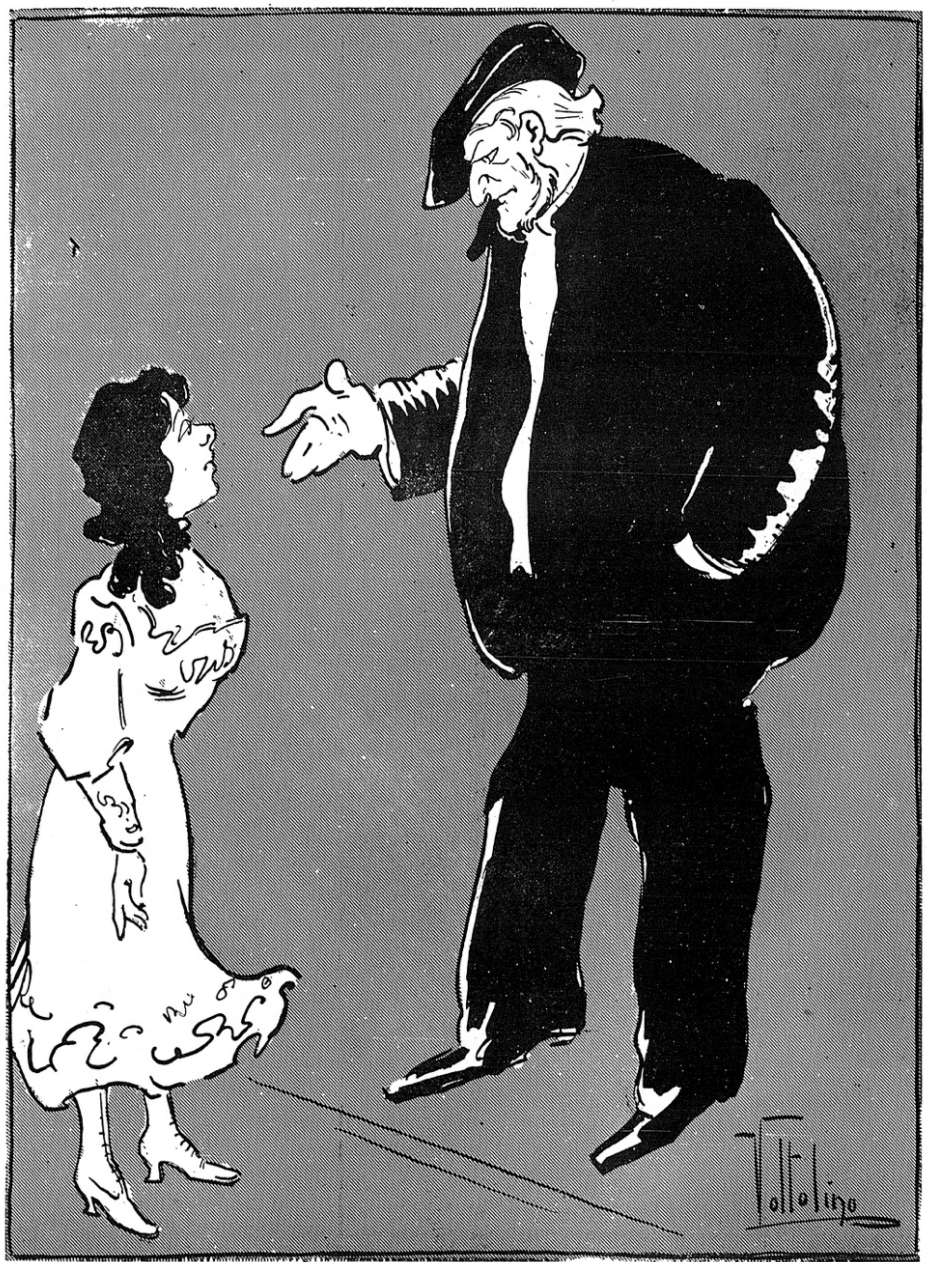

WAGNER - Não faça caso, menina, quando elle fala de mim è ainda mais perverso... .

Figura 4-Charge de Voltolino satirizando Félix de Otero por sua crítica a Guiomar Novaes (O Pirralho, n. IIo, 27 de setembro de I9I3, p. 3) 


\section{O. gumprimento do maestro Brotero (lo be dissi che illo_dava goice)}

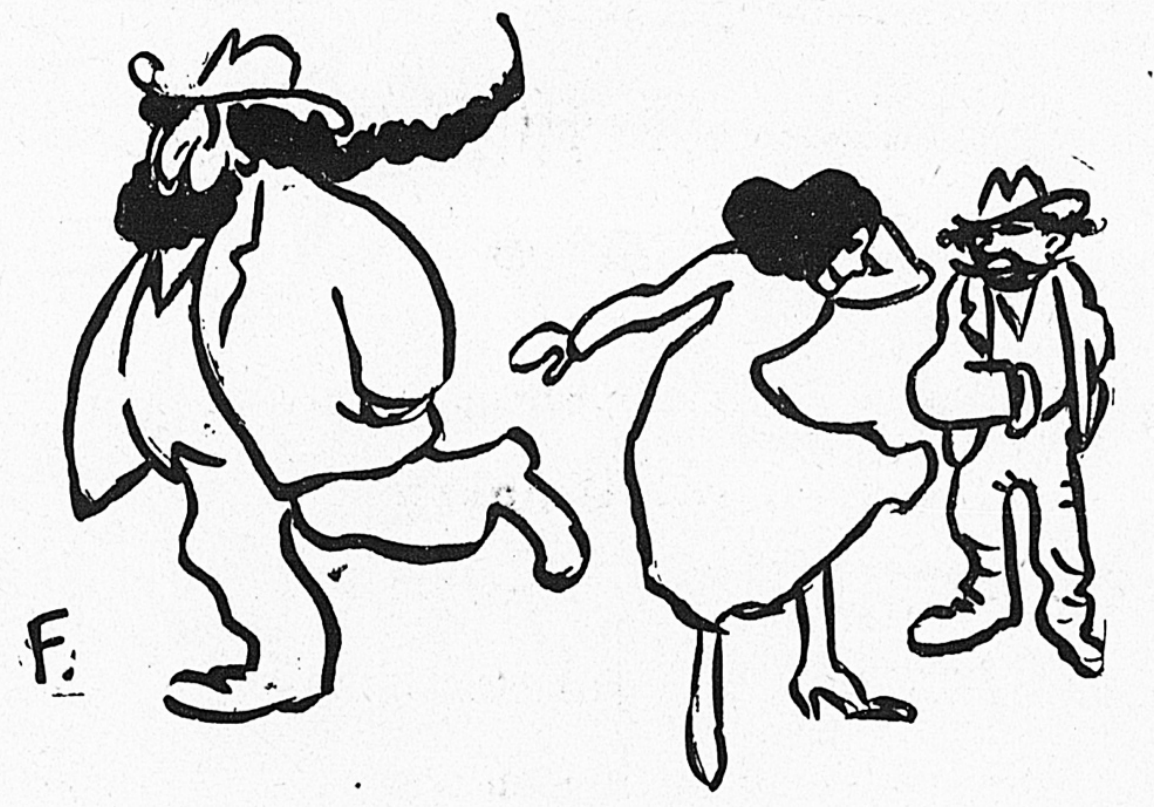

J. Bananere - Eh I Guiomara, non ligue !... Istu é révia delli, pur causa che vucê non prendeu musiga agiundo c'oo'li.

Figura 5 - Juó Bananère satirizando Félix de Otero por sua crítica

a Guiomar Novaes (O Pirralho, 4 de outubro de I9I3, p. 2)

\section{Glórias PAULISTAS NA CAPITAL FEDERAL}

Em julho de I9I4 o escritor e jornalista Amadeu Amaral comemorava em sua coluna no Estado o sucesso de alguns músicos paulistas no Rio de Janeiro e na Europa. O amor-próprio dos paulistas rejubilava, dizia ele (O Estado de S. Paulo, n. I2.983, 8 de julho de I9I4, p. 4).

Amaral referia-se aos êxitos de Antonietta Rudge, Guiomar Novaes e Walter Burle Marx, todos pianistas, e do violinista Francisco Chiaffitelli, cujos concertos repercutiram bem na imprensa carioca. A esses sucessos somavam-se ainda boas notícias vindas da Europa sobre a violinista Celina Branco, que estudava no Conservatório de Bruxelas, e o tenor José Bustamante Camargo, que cantava em Paris (O Estado de S. Paulo, n. I2.977, 2 de julho de I9I4, p. Io). Isso provava a Amaral que São Paulo era mais do que a terra do café: havia um pequeno foco de vida artística.

Esse reconhecimento público nos indica que o pianismo paulistano havia 
alcançado um novo estágio, para o qual foram decisivos os sucessos obtidos por Antonietta Rudge e, principalmente, Guiomar Novaes, em concertos dados no Rio de Janeiro entre junho e julho de I9I4. O próprio texto de Amaral ecoava notícias saídas na imprensa carioca e prontamente repercutidas na paulista.

Um dos assuntos desse diálogo público feito nas páginas dos jornais era uma conversa surgida em uma recepção oferecida pelo poeta e escritor Coelho Netto em sua casa no Rio de Janeiro. Nessa conversa, publicada em O Paiz, cogitava-se a promoção de um concerto com Guiomar e Antonietta juntas. A ideia causara enorme entusiasmo entre os convidados, e logo se acrescentou às duas a violinista Paulina d'Ambrósio. Por fim, o jornal lembrava que as "três distintas patrícias, três glórias nacionais [...], por uma curiosa coincidência, são elas três [...] nascidas em S. Paulo" (O Estado de S. Paulo, n.I2.977, 2 de julho de I9I4, p. Io). Publicada na imprensa carioca a Io de junho, a notícia foi republicada na imprensa paulista no dia seguinte.

Guiomar estreou no Theatro Municipal do Rio de Janeiro em 25 de junho de I9I4. Em sua crítica sobre o espetáculo, o calejado e temido crítico Oscar Guanabarino começava revelando o principal motivo que o fizera sair de casa: a familiaridade com o nome da pianista paulista. A razão para escutá-la era satisfazer sua curiosidade sobre os verdadeiros méritos de Guiomar - se ela fazia jus aos elogios que a precediam. Afinal, argumentava ele:

\begin{abstract}
Alguém, por ela, incumbira-se de transcrever na imprensa desta capital tudo quanto a seu respeito se publicava na Europa [...]; mas, devido à experiência de longos anos de tirocínio, púnhamos de reserva o que a seu respeito líamos, ainda que sentíssemos certo prazer tendo conhecimento de mais uma patriciasinha, que, pelo seu talento, atraiu sobre si as atenções do público e da imprensa de importantes capitais europeias. (O Paiz, n.Io.855, 27 de junho de I9I4, p. 3).
\end{abstract}

O depoimento de Guanabarino é valioso por vir de um ator envolvido nos meandros da imprensa. Os seus anos de "tirocínio" levaram-no a suspeitar da idoneidade ou competência de seus colegas europeus. O crítico conhecia as convenções de seu ofício, das críticas encomendadas e dos concertos não assistidos, por exemplo. Ou seja, os críticos não eram confiáveis. O texto de Guanabarino mostra igualmente o papel da imprensa em criar, alimentar e amplificar expectativas e afetos: mesmo que os elogios feitos a Guiomar fossem falsos, eles eram prazerosos, alimentando em Guanabarino um misto de sentimentos patrióticos e afetivos.

Segundo o jornal O Paiz (n. I0.854, 26 de junho de I9I4, p. 4), o Theatro Municipal não estava completamente tomado, mas sua ocupação era "mais que regular". 0 público, por sua vez, esteve entusiasmado durante todo o recital, que fora "magnífico", "caloroso", "verdadeiramente impressionante".

A descrição feita no Jornal do Commercio foi em outra direção, carregada nas tintas: Guiomar levou "frêmitos à alma do carioca", foi "aplaudida com delírio", "inflamou o espírito do auditório para as manifestações de glorificação”. Tudo isso não se dera por motivos patrióticos ou vaidades: 
a causa de toda aquela exaltação que se processou rapidamente, começando por demonstrações de agrado, crescendo num impulso de admiração, avolumando-se nos gestos irreprimíveis dos aplausos amplificando-se nas aclamações e explodindo em uma apoteose, teve origem na grandeza artística que a excelsa pianista revelou. (Jornal do Commercio, n. I76, 26 de junho de I9I4, p. 5).

E foi esse tom "apoteótico" que predominou na grande imprensa carioca no resto da passagem de Guiomar Novaes pelo Rio de Janeiro. Após o sucesso do primeiro concerto, um segundo foi organizado. O Teatro Lírico foi escolhido pela necessidade de um "teatro maior para conter todos os admiradores da brilhante pianista que ainda não puderam aplaudi-la no primeiro concerto" (Jornal do Commercio, n. I79, 29 de junho de I9I4, p. 6). Tomado por uma "enchente", o "velho teatro, cujas vastas dimensões são bem conhecidas, regurgitava”, foi um "verdadeiro delírio”. Ao final, a multidão que se aglomerou à porta do teatro esperando pela pianista cercou o carro que a levaria e "acompanhou-a até longa distância, vitoriando-a sem interrupção" $(O$ Paiz, n.Io.862, 4 de julho de I9I4, p. 3).

Um terceiro concerto foi marcado no Salão de Empregados do Comércio, outros dois no Teatro Lírico. O penúltimo foi intitulado Festival Artístico Popular por ter ingressos a preços módicos, dando oportunidade a pessoas de menor poder aquisitivo. No derradeiro e último concerto, Guiomar se apresentou como solista convidada pela Sociedade de Concertos Sinfônicos ${ }^{18}$.

O anonimato é um problema para quem usa textos jornalísticos como fonte histórica. Em razão das muitas pessoas e atividades envolvidas na produção dos textos (repórteres, redatores, revisores, chefes de redação, linotipistas, diagramadores, ilustradores etc.), é praticamente impossível identificar as alterações ocorridas durante o processo editorial. Ainda que a autoria nem sempre seja conhecida, os objetivos e expectativas criados pelos textos jornalísticos são identificáveis.

Segundo Oscar Guanabarino, alguém promoveu o nome de Guiomar Novaes na imprensa carioca durante o período em que ela estivera na Europa. Guiomar não possuía idade, autonomia nem contatos para tal. Duas pessoas em seu círculo íntimo poderiam ter conduzido essa campanha: Luigi Chiaffarelli e Gelásio Pimenta. Chiaffarelli é uma opção óbvia, afinal ele fora o professor da pianista. Mas Gelásio é o candidato mais forte. Ele apoiou Guiomar quando ela ainda era menina. Também era um homem da imprensa e havia passado por diversos jornais e revistas paulistas antes de criar A Cigarra, periódico que marcou época em São Paulo. Sua revista estava engajada na promoção do "progresso paulistano", da pujança do café e dos feitos realizados no estado e na cidade de São Paulo's.

Desde o início, Guiomar Novaes sempre estave presente na revista. No primeiro número, de março de I9I4, foi uma fotografia sua; no número 6, a coluna Consultório Grafológico era inaugurada com a análise de sua caligrafia, que revelava:

I8 Datas dos concertos de Guiomar no Rio de Janeiro: 25 de junho no Theatro Municipal; 2 de julho no Teatro

Lírico; I2 julho, Salão dos Empregados do Comércio; em 23 de julho foi o Festival Artístico Popular; 25 de julho,

Sociedade de Concertos Sinfônicos.

I9 Sobre essa fase do periodismo paulista, ver: Martins, 200I, p. 532-538. 
Espírito e coração de eleição; inteligência lúcida e criadora; grande sensibilidade feminina. Paixão profunda, alucinada pela arte. Amor ao sucesso, à glória, à celebridade.

[...]

Não é vaidosa, nem orgulhosa, nem ambiciosa, porque em sua alma tudo é equilíbrio e harmonia. O seu grafismo tem um aspecto de uma partitura, como reflexo que é do seu grande talento de virtuose musical. (A Cigarra, n. 6, 25 de junho de I9I4, p. s.n).

Como Guiomar poderia ter amor ao sucesso e não ser ambiciosa, não foi explicado.

Após os êxitos no Rio de Janeiro, em julho de I9I4, Guiomar foi capa de A Cigarra (Figura 6). Gelásio Pimenta, que tinha relação pessoal ela ${ }^{20}$, usou-a seu favor para promover seu periódico. No carnaval de I9I5 Guiomar estava entre as 32 moças que desfilaram no corso da Avenida Paulista no caminhão de A Cigarra; em maio ela participou de um sarau na casa de Pimenta, evento que logicamente foi registrado em uma foto nas páginas da revista (A Cigarra, n. I9, fevereiro de I9I5; n. 2I, maio de I9I5).

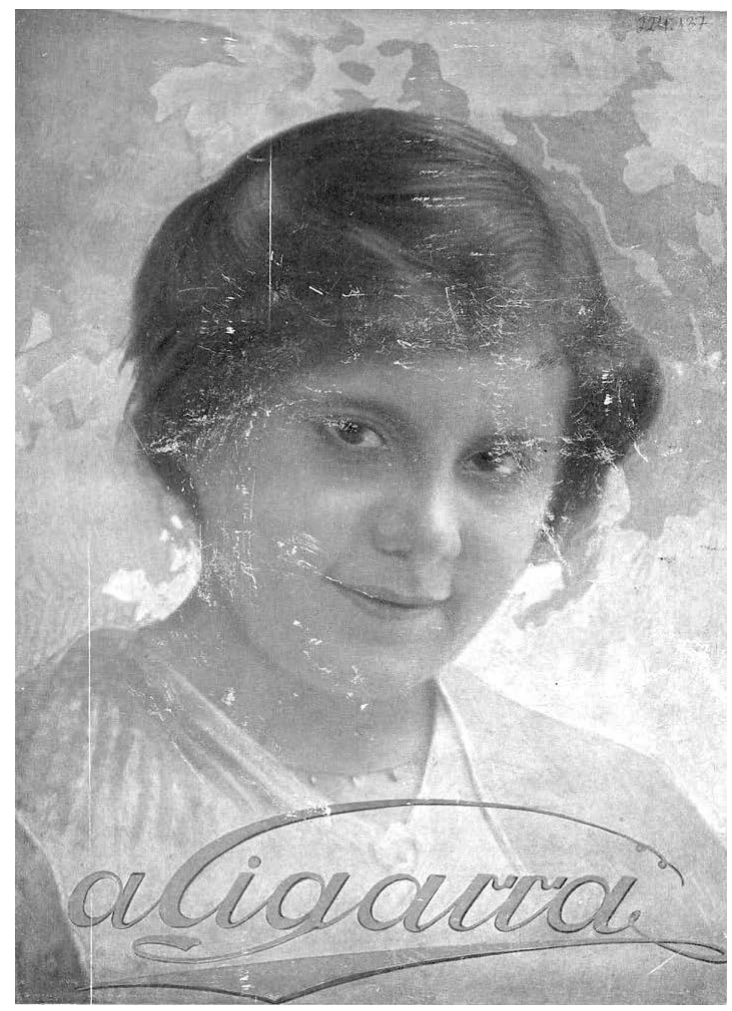

Figura 6 - Guiomar Novaes na capa da revista A Cigarra, n. 8, agosto de I9I4

20 O necrológio de Gelásio Pimenta no Correio Paulistano (2I de setembro de I924, p. 3) menciona a profunda admiração dele por Guiomar. 
Pimenta logo deve ter intuído que Guiomar interessava a uma parcela de leitores que desde cedo ele procurou cativar: as alunas do Conservatório Dramático e Musical de São Paulo. A Cigarra publicava regularmente notícias e fotos sobre a escola. Uma delas retratava o veterano João Gomes de Araújo com suas alunas de canto. Um rapaz alto e novo destoava no grupo: era Mário de Andrade (Figura 7).

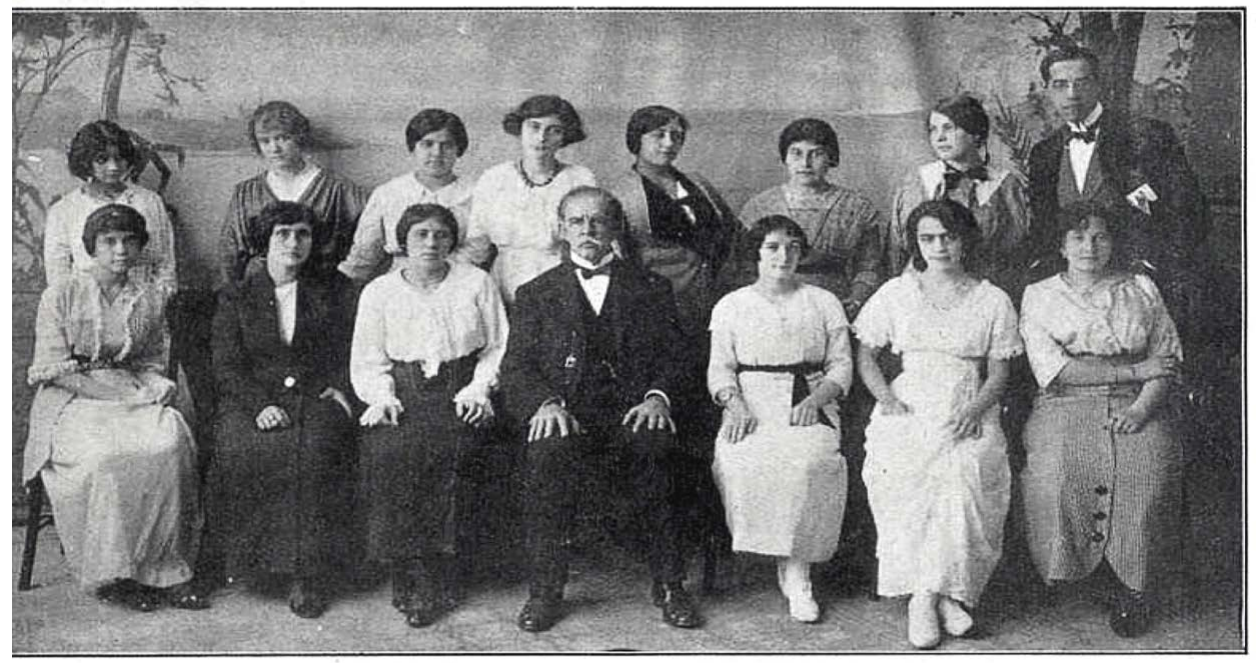

Figura 7 - João Gomes de Araújo com suas alunas de canto do Conservatório Dramático e Musical de São Paulo e Mário de Andrade, em I9I4 (A Cigarra, n. 7, I6 de setembro de I9I4, p. s. n.)

Estevam Lucchesi, reformador e afinador de pianos, também percebeu que a associação à imagem de Guiomar Novaes era uma boa estratégia de marketing. Um anúncio seu em $O$ Estado de S. Paulo reproduziu um bilhete manuscrito de Guiomar em que ela recomendava sua oficina, cujos serviços "rivalizam aos melhores profissionais" da Europa (Figura 8). 


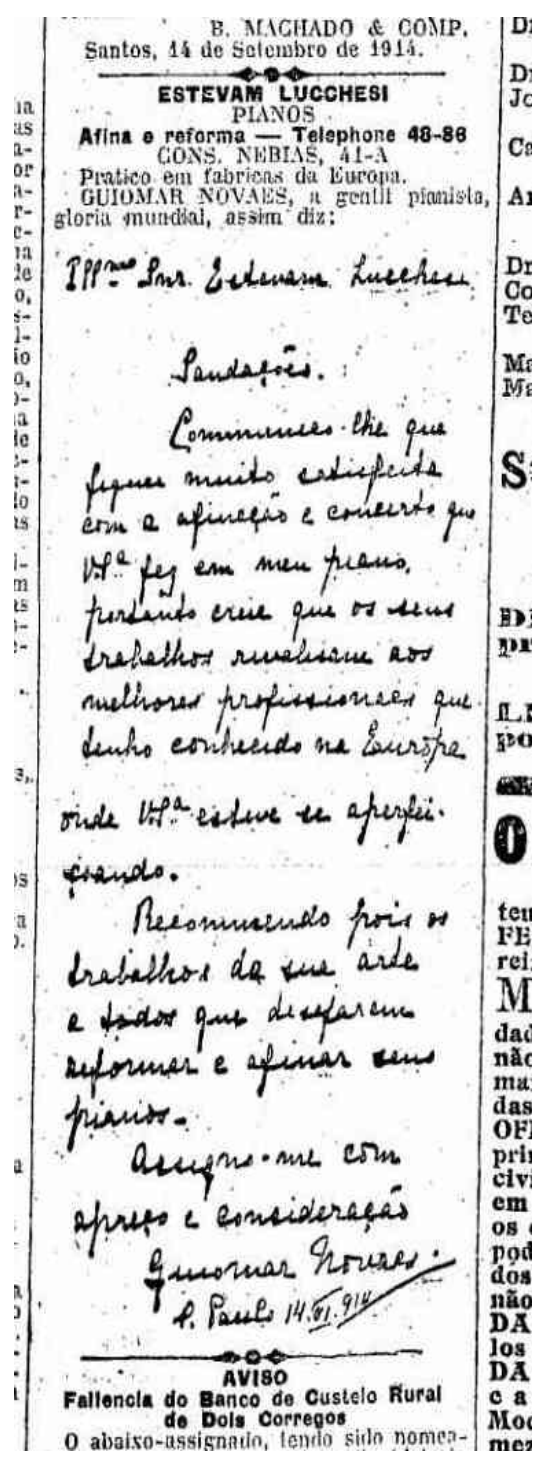

Figura 8 - Anúncio de Estevam Lucchesi com a recomendação de Guiomar Novaes sobre seus serviços de reforma e manutenção ( $O$ Estado de S. Paulo, n. I3.052, I5 de setembro de I9I4, p. 9)

\section{Guiomar Novaes, um SÍMBolo NACIONAL}

Em I9I3 Guiomar Novaes voltava da Europa laureada pelas plateias e críticos europeus. Quem foi à sua estreia no Theatro Municipal de São Paulo foi para ouvi-la e para coroá-la. Os cinco concertos no Rio de Janeiro, em I9I4, confirmavam à capital 
do país a alta reputação que a acompanhava. Mais que paulista, naquele momento Guiomar Novaes se tornava uma artista brasileira.

O fenômeno Guiomar Novaes ultrapassou o caráter de prova do sucesso do projeto civilizatório republicano. Proclamada a República, os vários grupos que derrubaram o Império passaram a lutar pela imagem que o novo regime deveria projetar em uma batalha por símbolos, alegorias e mitos, a batalha pela "formação das almas”. Segundo José Murilo de Carvalho, a inexistência de uma identidade coletiva era uma das dificuldades que o novo regime enfrentava para legitimar-se. Por isso, "a busca de uma identidade coletiva para o país, de uma base para a construção da nação seria a tarefa que iria perseguir a geração intelectual da Primeira República” (CARVALHO, 20I2, p. 32).

Guiomar foi importante de duas maneiras ao menos na construção dessa identidade coletiva. A primeira foi como símbolo nacional, alguém com quem as camadas urbanas poderiam se identificar, mulheres inclusive. A segunda era a possibilidade que seus concertos proporcionavam ao público de exercitar in loco o sentimento patriótico.

Para DeNora a performance musical atua como agente estruturador de categorias e de experiências sociais. A execução das obras de piano de Beethoven em Viena ajudou a estruturar percepções sobre formas de tocar masculinas e femininas. Ou seja, tocar a música de Beethoven era uma maneira de desempenhar distinções (construídas) de gênero (DeNORA, 2002). Então, podemos dizer que a performance contribuiu para a criação de uma identidade, nesse caso, a identidade de gênero.

A Grande fantasia triunfal sobre o Hino Nacional Brasileiro, de Louis Moreau Gottschalk, foi um dos cavalos de batalha de Guiomar Novaes. Durante toda sua carreira ela era recorrentemente pedida no bis de seus concertos. Em I897, seu professor Luigi Chiaffarelli descreveu músicas desse tipo como "espalhafatosas, steeple-chases [corridas de obstáculos] dos dedos, dos punhos, de todo o corpo. - Mas tanto barulho, ia eu dizer suadouro, por quê? Para fazer efeito. Uma parte do público gosta" (Revista Música para Todos, abril de I897, p. I9I).

A corporalidade que a música demandava da intérprete também foi incorporada pelo público que, com o tempo, passou a colocar-se em pé durante sua execução. Ou seja, o público comportava-se como se o próprio hino nacional estivesse sendo tocado. Guiomar tocava a Grande fantasia regularmente desde I906; a primeira notícia mencionando tal comportamento da plateia é de I9I4 (O Estado de S. Paulo, n. I2.845, I9 de fevereiro de I9I4, p. 4). Ao levantar-se de suas cadeiras, o público participava de uma ação coletiva realizando e experimentando um sentimento patriótico. O deslumbramento provocado por Guiomar inflamava o orgulho nacional da plateia, criava-se pela música uma identidade coletiva forte.

Nesse sentido, cabe lembrar que, antes dela, o único músico brasileiro que alcançou semelhante projeção nacional e internacional foi o compositor campineiro Antônio Carlos Gomes, com a ópera O guarani, em I870. Após o êxito nos Estados Unidos, a partir de I9I5 Guiomar superou Carlos Gomes e colocou-se em um patamar que nenhum outro artista brasileiro havia experimentado até então: ser reverenciado na Europa e na América do Norte, pelo Novo e pelo Velho Mundo. 


\section{CONSIDERAÇõES FINAIS}

A altíssima reputação conquistada por Guiomar Novaes não garantiu a salvaguarda de sua memória documental - parte importante dela acabou na rua em uma caçamba de entulho. $\mathrm{O}$ desinteresse dos herdeiros de seu acervo contribuiu para sua fragmentação, e parte importante quase foi tragicamente perdida. A natureza e o status de sua produção artística são fatores que contribuíram para esse destino como intérprete, sua produção é considerada recriação de obras originais de outros artistas. Por isso, acervos como o dela não atraem o interesse das instituições de memória musical, que tradicionalmente se ocupam em preservar obras originais produzidas por compositores. Essa distinção entre criação e recriação, entre compositor e intérprete, reproduz a clivagem entre atividades consideradas masculinas e femininas.

O uso da imprensa periódica como fonte histórica tem sido a principal solução encontrada para superar a falta de fontes organizadas sobre Guiomar Novaes. Mas a crítica ao uso das informações encontradas em jornais e revistas precisa ir além dos textos em si. É necessário analisar as orientações editoriais e os interesses comerciais dos veículos, o público leitor e o emprego de recursos técnicos e estilísticos, como fotografias, ilustrações, títulos, diagramação do conteúdo etc. As coberturas do concerto de estreia de Guiomar Novaes no Theatro Municipal feitas pelo Correio Paulistano e $O$ Estado de S. Paulo mostram como esses elementos foram usados para mobilizar expectativas e afetos no público paulistano.

As análises da carreira de Guiomar Novaes insistem no caráter transgressor às normas sociais que sua atividade concertística representava: ao invés dos filhos e da família, concertos e recitais. A análise da construção social de sua reputação de artista indica a necessidade de matizar esta afirmação, de investigar os limites transponíveis e instransponíveis nas atividades musicais. Nas fontes consultadas, não se encontraram reações repressivas que colocassem em risco a carreira de Guiomar. A crítica de Félix de Otero alude a preconceitos de gênero típicos da época: falta de vigor intelectual (repertório de pouca responsabilidade) e físico (falta de dinâmica musical). Mas as censuras de Otero foram violentamente combatidas por Vicente de Carvalho, ou seja, havia quem a apoiasse e a defendesse.

Certamente as fontes utilizadas aqui possuem limites. As cartas de Guiomar poderiam explicar o que ela achou das críticas e por que ela mesma não se defendeu das admoestações de Otero. Mas a defesa enfática que Vicente de Carvalho e outros fizeram dela mostra que havia pessoas dispostas a colaborar para que ela rompesse as fronteiras do casamento e da maternidade.

Por último, é preciso refletir se o exemplo de Guiomar Novaes pode ser usado como modelo. Ela foi uma virtuose, ela alcançou um nível de excelência artístico altíssimo, muito superior ao de outros pianistas, que, portanto, tinham limites e horizontes de atuação imensamente mais modestos que os de Guiomar. Seria interessante, então, investigar até que ponto a raridade de sua excelência e o símbolo nacional que ela se tornou contribuíram para a aceitação da transgressão que ela representava. 
FERNANDO PEREIRA BINDER é professor de História da Música da Escola Municipal de Música da Fundação Theatro Municipal de São Paulo. E-mail: fernandobinder@yahoo.com.br

\section{REFERÊNCIAS}

BECKER, Howard Saul. Art worlds. Berkeley: University of California Press, I982.

BELCHIOR, Pedro; ANTUNES, Anderson. Presença de Arminda: processos de construção da memória no Museu Villa-Lobos (I956-I985). Museologia e Patrimônio, Programa de Pós-Graduação em Museologia e Patrimônio da Unirio, v. 4, n. 2, p. 5I-74, 20 II.

BINDER, Fernando Pereira. O silêncio dos arquivos: dos manuscritos do século XVIII à memória de Guiomar Novaes. Comunicação. In: SEMINÁRIO INTERNACIONAL ARQUIVOS, MULHERES E MEMÓRIA, I,Centro de Pesquisa e Formação do Sesc e Instituto de Estudos Brasileiros da USP, São Paulo, 20I7.

. Profissionais, amadores e virtuoses: piano, pianismo e Guiomar Novaes. Tese (Doutorado em Música). Escola de Comunicações e Artes, Universidade de São Paulo, São Paulo, 2018.

CARVALHO, Dalila Vasconcelos de. O gênero da música: a construção social da vocação. São Paulo: Alameda, 2012.

CARVALHO, José Murilo de. A formação das almas: o imaginário da República no Brasil. São Paulo: Companhia das Letras, I990.

CITRON, Marcia J. Gender and the musical canon. Cambridge: Cambridge University Press, I993.

DeNORA, Tia. Music into action: performing gender on the Viennese concert stage, I790-I8Io. Poetics, v. 30, n. I, 2002, p. I9-33.

GREEN, Lucy. Music, gender, education. Cambridge: Cambridge University Press, I997.

LE GOFF, Jacques. História e memória. 5. ed. Campinas: Editora da Unicamp, 2003.

LIMA, João de Souza. Moto perpétuo: a visão poética da vida através da música - autobiografia do maestro Souza Lima. São Paulo: Ibrasa, I98I.

MADIO, Telma Campanha de Carvalho. A fotografia na imprensa diária paulistana nas primeiras décadas do século XX: O Estado de S. Paulo. História, São Paulo, v. 26, n. 2, 2007, p. 6I-9I.

MARTINS, Ana Luiza. Revistas em revista: imprensa e práticas culturais em tempos de República, São Paulo (I890-I922). São Paulo: Edusp/Fapesp, 200I.

MEDEIROS, Luciana; SAMPAIO, João Luiz. Guiomar Novaes do Brasil: a trajetória da pianista em Nova York. São Paulo: Kapa, 20II.

OLIVEIRA, José da Veiga de. Guiomar Novaes, uma plenitude de artista. Revista do Instituto Histórico e Geográfico de São Paulo, São Paulo, IHGSP, v. CXCIV, n. 77, I98I, p. 47-70.

ORSINI, Maria Stella. Guiomar Novaes: uma vida, uma obra. São Paulo. V. I. Tese (Livre-docência). Escola de Comunicações e Artes, Universidade de São Paulo, São Paulo. I988. . Guiomar Novaes: uma arrebatadora história de amor. São Paulo: Companhia Ilimitada, I992. 
SEVCENKO, Nicolau. Orfeu extático na metrópole: São Paulo, sociedade e cultura nos frementes anos 20. São Paulo: Companhia das Letras, I992.

SILVA, Eliana Maria de Almeida Monteiro da. Clara Schumann: compositora $x$ mulher de compositor. São Paulo. Dissertação (Mestrado em Música). Escola de Comunicações e Artes, Universidade de São Paulo, São Paulo, 2008.

SPECHT, Thamires. Acervo de Guiomar Novaes é encontrado em Piracaia (SP), e é enviado ao IPB. Io ago. 20I8. Disponível em: <http://institutopianobrasileiro.com.br/post/visualizar/Acervo_de_Guiomar_Novaes_e_encontrado_em_Piracaia $>$. Acesso em: 20 set. 2018.

THALASSA, Ângela. Correio Paulistano: o primeiro diário de São Paulo e a cobertura da Semana de Arte Moderna. Dissertação (Mestrado em Comunicação e Semiótica). Pontifícia Universidade Católica de São Paulo, 2007.

THEATRO Municipal de São Paulo: Ioo anos - Palco e plateia da sociedade paulistana. Texto de Marcia Camargos. Ensaio fotográfico de Cristiano Mascaro. São Paulo: DMP, 20 II.

TOFFANO, Maria Jaci. As pianistas dos anos I920 e a geração jet-lag: o paradoxo feminista. Brasília: EDU -UNB, 2007. 